\title{
Changing landscape of public health and medical education curriculum
}

Ghana Med J 2018; 52(3): 115 doi: http://dx.doi.org/10.4314/gmj.v52i3.1

The landscape of public health in many sub-Saharan African countries has been changing rapidly over the past few decades. Marked changes have been seen in the demographic structure of populations, economics, lifestyle changes, social upheavals (war and migration) and these have impacted disease patterns.

The population structure indicates that the workforce age band is showing a bulge and life expectancy is rising with an increasingly elderly population. The economic status of many of these sub-Saharan countries are said to be improving with changes in status from low income to low middle income status.

Newer health technologies have influenced the diagnosing, assessment and treatment of health problems. Public health challenges are transitioning from communicable diseases to non-communicable diseases, with no discernible reduction in infections, such that subSaharan African countries are said to be suffering from the double burden of disease. This change has risen to such levels that non-communicable diseases are rapidly becoming major causes of morbidity and mortality. While some communicable diseases remain endemic, several strategies exist for minimising their health effects. Outbreaks of new and emerging infections have exposed the inadequacies of the health systems, such as occurred with the recent outbreak of Ebola virus disease in West Africa.

A health workforce is one of the major ingredients for an efficient health system. The other elements of the health system are Service Delivery, Information, Medical products/devices, Health Financing and Leadership/governance. Health Systems Performance reflects the Medical Education in a country. (Professor E. Paintsil, personal communication, 2018).

The transitions mentioned above have important effects on the health system. These transitions are influenced by globalisation and they also have an effect on health professional's education and medical education curriculum development. Many African medical schools hitherto have used either a teacher-centred curriculum (TCC) or student-centred curriculum (SCC) in their teaching and learning environment to good effect.

In this issue of the journal (page 116-124) Ogun O. A and his colleagues report on students' perspective on curricula for medical education in two Nigerian medical schools.
The study used the Dundee Ready Education Environment Measure (DREEM) questionnaire to examine the hypothesis that the mean total DREEM score of the SCC school would be significantly higher than that of the TCC School. The results indicated that there was no statistically significant difference between the overall DREEM score for the two schools. There is a general shift from teacher-centred curriculum to student-centred curriculum and other teaching models. Indeed, many medical schools in sub-Saharan Africa have also introduced Community Based Education and Service (COBES) as part of their curriculum.

Curricula for medical education should be consistent with the changing medical landscape and should support improvements in health system performance. This means that medical education curriculum should be dynamic and lend itself to change in the light of prevailing evidence on health system needs and performance. Besides the competencies in diagnosing common infections should be added training in research to enable new graduates provide answers to the myriad of health problems they will face as a consequence of the changes.

"Medical doctors are products of the curriculum they are trained with. The rapidly changing needs, expectations and demands of our populations for safe, accessible and personalized care means that the doctors we are graduating nowadays must not only possess knowledge and skills, but also, they must be motivation-ready, entrepreneurial-ready and innovation-ready. We must critically and dispassionately reflect on how we are training our medical students, and to ask ourselves whether the training they receive prepares them to meet the challenges, the healthcare needs and expectations of the communities they serve. (Professor Harold AmonooKuofi, personal communication, 2018)

Traditional medical school curricula have been described by some as "narrow" and "inflexible". There is therefore the need to consider radical curricular reforms to meet today's demands.

\section{David Ofori-Adjei, FGCP, FGA \\ Ghana Medical Journal \\ E-mail: editor@ghanamedj.org \\ Conflict of interest: None declared}

